\title{
A SIMPLE MICRO ELECTRET POWER GENERATOR
}

\author{
Hsi-wen Lo ${ }^{1}$, Rus Whang ${ }^{2}$, and Yu-Chong Tai ${ }^{1}$ \\ ${ }^{1}$ California Institute of Technology, California USA \\ ${ }^{2}$ University of Cambridge, Cambridge UK
}

\begin{abstract}
We developed a novel, yet simple, micro electret power generator prototype for low-frequency energy harvesting applications. In this prototype, two electrodes of the power generator are placed on the stator. The rotor is only a plate with metal strips of half of the spatial frequency of the stator plate. The packaging is to simply fix the stator to a container and put the rotor directly on top of the stator. CYTOP, a MEMS-compatible perfluoropolymer, served as the electret material and charged with corona charging. The power output was $2.267 \mu \mathrm{W}$ at $60 \mathrm{~Hz}$.
\end{abstract}

\section{INTRODUCTION}

During last decade, much attention has been drawn towards devices that can harvest vibration energy from the environment and have the potential to replace batteries in handheld devices or wireless sensors. Most of the published works were focused on only two approaches: the electromagnetic paradigm [1-3], and the piezoelectric paradigm [4-6]. However, these approaches all have to count on the springproof-mass design so their performance is always limited to certain narrow bandwidth around the mechanical resonant frequency, while natural harvestable vibration power spectrum usually spans from low to $\sim 100 \mathrm{~Hz}$ with higher energy in the low frequency end. To overcome these fundamental problems, the third approach of electret power generators without springs (hence no resonant frequency) emerged to have a major advantage of broadband operation. For examples, Boland et al demonstrated the first liquid-rotor Teflon AF electret power generator of $0.43 \mu \mathrm{W}$ production with a $28 \mathrm{~Hz}$ shaker [7]. Tsutsumino et al showed a linear solidrotor power generator of $37.7 \mu \mathrm{W}$ production with a $20 \mathrm{~Hz}$ shaker [8].

As for the electret material, different materials have been examined as electrets [9]. Teflon AF charged with a back-lighted thyratron was used in Boland et al's work. Tsutsumino et al discovered that CYTOP, an amorphous perfluoropolymer from Asahi Glass Co., Ltd. can also work as an electret material [8]. CYTOP has also been demonstrated to be a better electret material than Teflon AF with higher charge density [8]. Taking this into consideration, we chose CYTOP as the electret material for our device.

\section{DEVICE DESIGN}

For electret power generators, the biggest issue is that they do require careful gap control between the rotor and stator; otherwise, these devices lose performance greatly [7] [8]. This stems from the fact that the two electrodes of the power generator are placed in such a way that one is on the rotor and the other is on the stator, as shown in Fig. 1, and the fact that power output depends on the capacitance between these two electrodes.

To overcome this issue, we developed a new electret generator design that requires no precise separation gap control and hence greatly simplify the packaging requirement. The schematic of this design is shown in Fig. 2. The device is made of two parts, the rotor and the stator. Both the two electrodes of the power generator are placed on the stator. The rotor has simply floating metal strips with $1 / 2$ of the spatial frequency of the electrodes on the stator. The packaging is to simply fix the stator to a container and put the rotor directly on top of the stator. The rotor and the stator are in mechanical contact, where the electret material, CYTOP for our devices, serves as the low-friction bearing.

\section{DEVICE FABRICATION}

The device consists of two parts, the rotor and the stator. Fabrication of the rotor and the stator started with a soda lime wafer. 1500-Angstron gold along with 200-Angstron chromium was thermally evaporated onto the soda lime wafer and patterned by photolithography and wet etching according to the design.

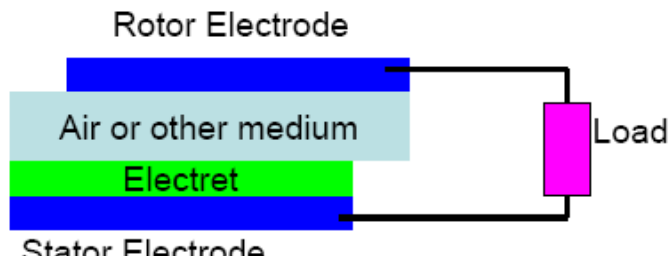

Figure 1. General design of an electret power generator 


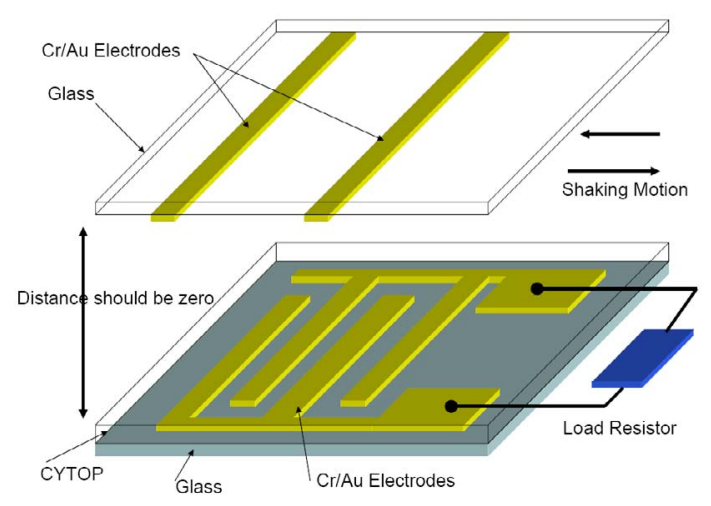

Figure 2. Schematics of the new electret power generator

The electrodes on the stator were $18 \mathrm{~mm}$ long and $1 \mathrm{~mm}$ wide with $50 \mu \mathrm{m}$ separation, and they are connected alternately.

The electrodes on the rotor were floating metal strips with $1 / 2$ of the spatial frequency of the electrodes on the stator. CYTOP (CTL-809M), as purchased from Asahi Glass Co., Ltd., was spincoated on the stator at a speed of $1000 \mathrm{rpm}$ for 20 seconds and soft-baked at $100^{\circ} \mathrm{C}$ for 30 minutes. This spin-coating process was repeated 7 times to obtain 20- $\mu \mathrm{m}$ thick CYTOP film. Finally the CYTOP film was fully cured at $185^{\circ} \mathrm{C}$ for 90 minutes. Fig. 3 shows the fabricated stator and rotor.

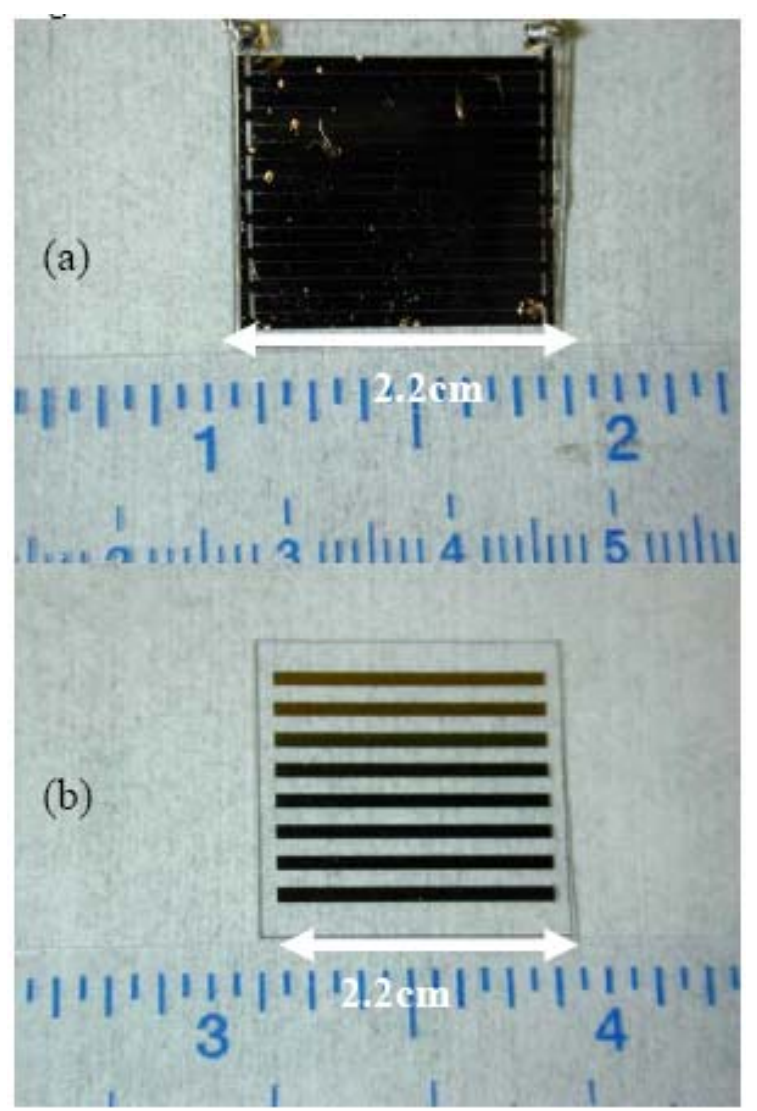

Figure 3. Fabricated devices: (a) the stator and (b) the rotor.
TABLE I.

CONDITIONS OF CORONA CHARGING

\begin{tabular}{|l|l|}
\hline Needle Voltage & $-6 \mathrm{kV}$ \\
\hline Grid Voltage & $-600 \mathrm{~V}$ \\
\hline Temperature & $100^{\circ} \mathrm{C}$ \\
\hline Charging time & 10 minutes \\
\hline
\end{tabular}

After fabrication, the CYTOP electret was charged by corona charging. The condition of the coronacharging is listed in Table 1 . The surface potential distribution after charging is shown in Fig 4. The average surface potential is around $-300 \mathrm{~V}$ and the average charge density is $0.5578 \mathrm{mC} / \mathrm{m}^{2}$.

\section{EXPERIMENTAL DETAILS}

The stator was glued onto a CNC-machined acrylic container. All necessary wires were soldered and the rotor was directly placed on top of the stator, as shown in Fig. 5. Power generation experiments were performed using a shielded box mounted to Labworks Inc. ET-132-2 electrodynamic shaker, which was driven sinusoidally by a HP33120A function generator through a power amplifier. The acceleration of the power generator was measured using an Endevco256HX-10 accelerometer. The shaking frequency was varied from $10 \mathrm{~Hz}$ to $100 \mathrm{~Hz}$. The micro electret power generator was connected to a resistive load and the voltage across the load was measured from a National Semiconductor LF356N op-amp used as a $10^{12} \mathrm{Ohm}$ input impedance voltage buffer.
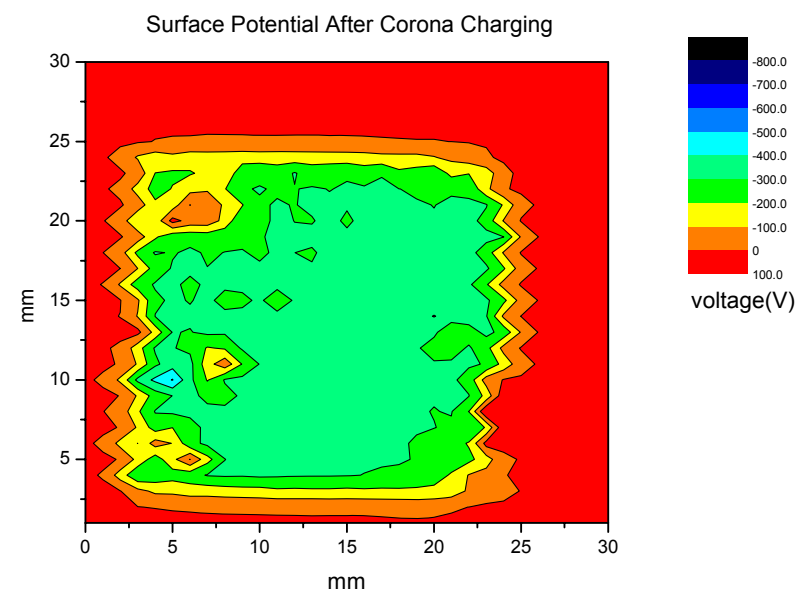

Figure 4. Distribution of surface potential after charging. (The red part is the area outside the device) 


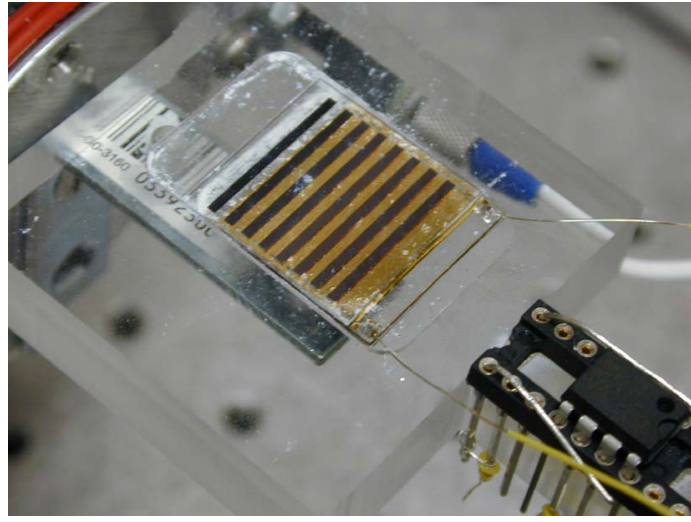

Figure 5. Testing setup

\section{RESUltS AND DisCUSSION}

As expected, the power generated depends on the load resistance and the driving frequency. Due to the capacitive nature of this device, there is an optimal load for the optimal power generation. Fig. 6 shows the power output versus load resistance at different driving frequencies. From the graph, it follows that the optimal load resistance is $40-50 \mathrm{M} \Omega$. Using this optimal $40 \mathrm{M} \Omega$ load resistance, the maximum power generated was $2.267 \mu \mathrm{W}$ at $60 \mathrm{~Hz}$. The time trace is shown in Fig. 7.

The relative low power output, compared to that of Ref. [8], can be attributed to the relatively low efficiency of corona charging. Under the same condition, the surface potential after charging was merely around $-300 \mathrm{~V}$, while that of Ref [8] was around $-1000 \mathrm{~V}$. Another possible cause would be that the rotor and stator plates are not perfectly flat and contact each other perfectly, leaving some air gaps in certain area. Further work is underway to boost the power output.

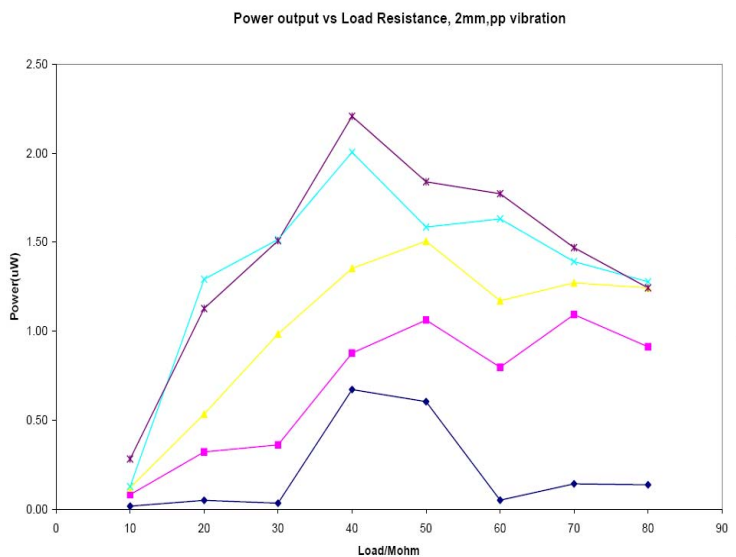

Figure 6. Power output versus load resistance at different frequencies

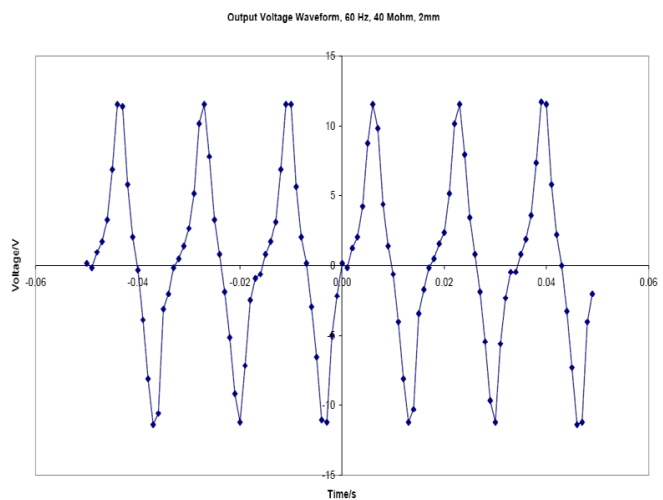

Figure 7. Time trace of power output at $60 \mathrm{~Hz}$ with load resistance of $40 \mathrm{M} \Omega$.

\section{Conclusions}

We have developed a simple micro electret power generator using CYTOP as the electret material. The micro power generator requires neither precise gap control nor complex packaging. The maximum power output obtained is $2.267 \mu \mathrm{W}$ at $60 \mathrm{~Hz}$ with load resistance of $40 \mathrm{M} \Omega$.

Further work is underway to boost power output as well as to integrate the device into other portable systems.

\section{ACKNOWLEDGEMENTS}

The authors would like to thank Mr. Trevor Roper for his assistance with equipment and fabrication, and Bionic Harvest Co., Ltd. for corona charging facilities. We would also thank Tanya Owen, Christine Matsuki and other members of the Caltech Micromachining Laboratory for their assistance. This work is supported partially by DARPA (Award \#0205-6-CE123).

\section{REFERENCES}

[1] S. Roundy, P. K. Wright, and K. S. J. Pister, "Microelectrostatic vibration-to-electricity converters", Proc. IMECE'02, 2002

[2] W. J. Li, Z. Wen, P. K. Wong, G. M. H. Chan, P. H. W. Leong, "A Micromachined Vibration-Induced Power Generator for Low Power Sensors of Robotic Systems", Proc, World Automation Congress: 8th Intl. Symp. on Robotics with Applications, 2000.

[3] C. B. Williams, and R. B. Yates,"Analysis of a Micro-electric Generator for Microsystems," Sensors and Actuators, A, Vol. 52, 1996, pp. 8-11.

[4] G. K. Ottman, H. F. Hofmann, A. C. Bhatt, and G. A Lesieutre, "Adaptive Piezoelectric Energy Harvesting Circuit for Wireless Remote Power Supply", IEEE transaction on Power Electronics, Vol. 17, No. 5, 2002.

[5] J.Kymissis, C. Kendall, J. Paradiso, and N. Gerhenfeld, "Parasitic power harvesting in shoes," in Proc. 2nd Int. Symp. Wearable Comput., Pittsburgh, PA, Oct. 19-20, 1998, pp. $132-139$

[6] N. Shenck and J. A. Paradiso, "Energy scavenging with shoemounted piezoelectrics," IEEE Micro, vol. 21, pp. 30-42, May-June 2001. 
[7] J. S. Borland and Yu-Chong Tai, "Liquid-Rotor Electret Micropower Generator", Solid-State Sensor, Actuator, and Microsystems Workshop, 2004.

[8] Takumi Tsutsumino, Yuji Suzuki, Nobuhide Kasagi, and Yoshihiko Sakane, "Seismic power generator using highperformance polymer electret", Proc. Int. Conf. MEMS'06, 2006.

[9] G. M. Sessler, "Electrets 3rd Edition”, Laplacian Press, 1998 